\title{
Discrimination of Various Vulnerable Groups - Perception Among the Students of the Faculty of Engineering ("Lucian Blaga" University of Sibiu)
}

\author{
Sorina CORMAN \\ "Lucian Blaga" University of Sibiu, Sibiu, Romania \\ sorina.corman@ulbsibiu.ro \\ Raluca SASSU \\ "Lucian Blaga" University of Sibiu, Sibiu, Romania \\ raluca.sassu@ulbsibiu.ro \\ Mihaela BUCUȚă \\ "Lucian Blaga" University of Sibiu, Sibiu, Romania \\ bucutamihaela@yahoo.com \\ Silviu MORAR \\ "Lucian Blaga" University of Sibiu, Sibiu, Romania \\ silviumorar@yahoo.com
}

\begin{abstract}
Alina UNGUREANU
Association for Development and Social Inclusion - ADIS, Bucharest, Romania allyungureanu@yahoo.com
\end{abstract}

\begin{abstract}
The purpose of this article is to highlight students' perception of the Faculty of Engineering concerning discrimination, particularly discrimination against certain vulnerable groups. This issue is part of a broader research that aims to assess the attitude of students towards discrimination.

The method used in the study is questionnaire-based survey. The questionnaire includes scales and subscales for measuring the attitudes of subjects, their emotions, cognitions and behaviors in relation to discrimination in general, and specifically in relation to certain vulnerable groups such as the Roma population, people with HIV/AIDS, people with a different sexual orientation or people with disabilities and mental illness.

The main results of our research have demonstrated that the students from engineering believe that there is discrimination within society, including at the level of educational institutions; the most discriminated category is Roma population.

These results reflect the importance of training engineering students in the field of ethics and non-discrimination. We conclude that there is a need of such courses in the context of promoting inclusive societies and of the rebirth of business ethics education at an international level.
\end{abstract}

Keywords: business ethics, engineering students, discrimination, vulnerable groups 


\section{CONTEXT}

The study presented in this paper was conducted within the project POSDRU/156/1.2/G/142145 "Medical higher education oriented towards a nondiscriminatory treatment of patients", developed in partnership between the "Lucian Blaga" University of Sibiu, as beneficiary, and the Association for Development and Social Inclusion (ADIS), as partner, during the period May $14^{\text {th }}, 2014$ - November $13^{\text {th }}, 2015$.

The project takes into account the fact that discrimination is one of the current issues in Romania and also that there are signs of aggravation of this phenomenon (according to the report "Perceptions and attitudes concerning discrimination in Romania", realized in 2012 and 2013 by TNS CSOP Romania, at the request of the National Council for Combating Discrimination). The phenomenon has also an impact in the economic field, in the context of social issues such as numerous corporate scandals and malpractice cases at international level (Jagger \& Volkman, 2014), growing lack of confidence in the correctness of business (Wankel \& Stanusch-Stachowicz, 2011) etc.

Business organizations are an integral part of economic, social and environmental systems. Therefore, the activities, structure and processes of these organizations must assume responsibility for the impact they have on those systems and the society that supports their existence (Sharma et al, 2010, Lauring and Bjerregaard, 2013, Goela and Ramanathan, 2014).

Activism in the business world also involves awareness of social problems. Business professionals should pursue profit, but at the same time must strive to achieve a balance between profit and responsibility, between variety and equality. People always exist as individuals in space and time. They are neither omnipotent nor omniscient, therefore are prone to making mistakes. On the other hand, they must take responsibility for their actions. No man can live outside the sphere of morality (Kacetl, 2014).

Ethics is even more important nowadays, as we live in an existential chaos, marked by different traditions, customs, cultures, religions, commercial interests which must be brought into harmony. The Romanian business environment needs a range of values and standards in making everyday decisions and in the elaboration of strategies for long-term development (Georgescu, 2012).

Today, ethics has an important place in all areas of life. Education is a fundamental process of each individual's becoming, therefore ethics in the educational system must occupy a very important place (Gülcan, 2015). The results of our study also suggest the need for and the importance of the introduction of ethics and non-discrimination courses in the curricula of future engineers.

People generally tend to follow social rules, except when it becomes too costly to do so (Engelen, 2011). In many cases existing institutional models of private business structures are proving to be expensive for the community, and thus there is a growing pressure for a change in the structure of these rules. Strategic corporate social responsibility measures 
(Corporate Social Responsibility) are potential ways of updating these rules. Other processes such as corporate governance, corporate and political mobilization (Corporate Outreach and Politics), rebuilding of the business (Business Process Redesign) and corporate business strategy are also tools and strategies that must be adopted by companies to comply with the ethical principles in business (Goela and Ramanathan, 2014).

Regardless of the numbers and the issues addressed by studies in the field, there is a research gap addressing some moral and social issues like attitude of discrimination among the groups of students. Business ethics has become an important part of study programs. Among the topics to be addressed are those related to cultural and linguistic diversity, different approaches to the ethical and moral principles in different cultures, ethical dilemmas (Kacetl, 2014).

In this article we intend to analyze the manner in which the students of the Faculty of Engineering ("Lucian Blaga" University of Sibiu) perceive discrimination in general, and in particular the discrimination against certain vulnerable groups, bearing in mind that "now more than ever the universities are called upon to prepare students who will raise ethical standards in the business world" (Kurpis, Beqiri \& Helgeson, 2008; Jagger \& Volkman, 2014).

The present paper addresses the main problem of perceiving discrimination against vulnerable groups, but also the possible intervention, among students, by designing courses about these issues.

\section{THE CONCEPT OF DISCRIMINATION}

Traditionally, discrimination has been defined as a negative and unjustifiable action which denies equal treatment of individuals or groups of individuals (Dipboye and Colella, 2004). Discrimination can occur on many levels: cultural, social, institutional, individual. There are two important concepts for the understanding of the process that generates discrimination. These are prejudice and stereotype (Dipboye and Colella, 2004).

Prejudice is defined most often as a negative and unfair attitude towards a social group or one person in that group. Like other attitudes, it provides a set-up for the interpretation of the environment by the attributes of good guy-bad guy, thus preparing the individual to take appropriate action. Prejudice can be generally reflected in assessments, and may include emotional reactions such as anxiety or contempt (Dipboye and Collela, 2004).

The stereotype is a generalization of beliefs about a group or its members, which is not justified because it reflects faulty or over-generalized thinking processes, impropriety, excessive rigidity, erroneous assignments, attitudes of prejudice, discriminatory behaviors (Dipboye and Collela, 2004). A stereotype represents a specific constellation of traits and roles associated with a group.

Because stereotypes function as coherent cognitive schemes, they influence how information about a group or a group member is acquired, processed, stored and recalled. Activating the stereotypes usually produces a processing of information which is an 
advantage for the stereotyped traits or other associations (Dipboye and Collela, 2004). In addition, people do not typically call the perceptual information that might refute the stereotype, but tend to view the group members that are outside the stereotype as exceptions or as a representative of a subtype of that group. As a result of these processes, stereotypes are resistant to change.

As far as the specific content of the stereotypes guides the praising of group members and defines appropriate roles and behaviors, stereotypes can determine how people respond in affective and behavioral manner towards the members of a group. Aside from their obvious expression in discrimination, stereotypes and prejudices can model interpersonal interactions in subtle but significant ways.

\section{METHOD}

In order to assess different aspects of the perception of discrimination among the students, we used a questionnaire with four scales: a scale for the perception about people with HIV/AIDS, a scale for the perception about people with different sexual orientation, a scale concerning perceived discrimination of people with mental illness and/or disabilities and a scale regarding discrimination of Roma population.

The first three are Likert scales, with the answers ranging from 1 (total disagreement) to 4 (total agreement).

The HIV/AIDS discrimination scale contains three subscales. The first has 27 items, with a score from 27 to 108 . The higher the score, the higher the declared discriminative attitude towards people with HIV/AIDS (e.g.: "I do not use the swimming pool at the same time with a person with AIDS/HIV"). The second one is a social distance scale, with 12 items, ranging from 1 to 10 . A higher score means a low social distance, thus represents a low discrimination (e.g.: "Rate from 1 to 10 - with 1 representing I DO NOT ACCEPT and 10 representing I TOTALLY ACCEPT - the extent of acceptation that a person with HIV/AIDS is your neighbor"). The third subscale evaluates knowledge about the HIV/AIDS disease. There are 16 items and the answers are true or false (e.g.: "HIV is transmitted by coughing and sneezing"). The score ranges from 0 to 16; a higher score indicates better knowledge about HIV/AIDS.

The "other sexual orientation" discrimination scale contains 29 items, with a score ranging from 29 to 116. A higher score means a higher tendency to discriminate people with other sexual orientation. (e.g.: "A person with other sexual orientation should be isolated from other people").

The mental illness discrimination scale and the disabilities discrimination scale evaluate the declared attitudes towards people with mental illness and with disabilities. The first one is a Likert scale, ranging from 1 (total disagreement) to 4 (total agreement), with 22 items. The score is ranging from 22 to 88 ; a higher score shows a higher tendency to discriminate people suffering from mental illness. The scale measuring the attitudes towards people with disabilities has 20 items. The respondent has to range from 1 (total disagreement) to 6 (total agreement). 
The scale evaluating the attitudes towards Roma population has three subscales and it based on a vignette. A situation is described and afterwards emotions, cognitions and behaviors regarding this situation are assessed.

The questionnaire was applied to 142 students from the Faculty of Engineering - "Lucian Blaga" University of Sibiu. Statistical processing was done using SPSS - version 22.

\section{RESULTS}

The comprehensive study conducted within the project in order to measure the attitude of discrimination of students from "Lucian Blaga" University of Sibiu included 1135 students, aged between 18 and 48 years; 372 male and 763 female. The number of participants allow comparative and correlational analysis between students from different faculties, revealing the problematic of discrimination in different fields of sciences, education and levels, helping to understand the phenomena of discrimination and to intervene adequately.

The structure of the respondents according to the faculties of belonging is as follows:

Table 1: Respondents in relation to the faculty of belonging

\begin{tabular}{|c|c|c|}
\hline Faculty & Frequency & Percent \\
\hline Law & 245 & 21.6 \\
\hline Letters and Arts & 52 & 4.6 \\
\hline Social And Human Sciences & 310 & 27.2 \\
\hline Engineering & 142 & 12.5 \\
\hline Sciences & 10 & 0.9 \\
\hline Medicine & 343 & 30.2 \\
\hline $\begin{array}{c}\text { Agricultural Sciences, Food Industry and } \\
\text { Environmental Protection }\end{array}$ & 10 & 0.9 \\
\hline Economics & 22 & 2 \\
\hline Theology & 1 & 0.1 \\
\hline Total & $\mathbf{1 1 3 5}$ & $\mathbf{1 0 0 . 0}$ \\
\hline
\end{tabular}

As Table 1 shows, 142 of the respondents were students within the Faculty of Engineering, and the results that we will further analyze will refer only to them.

Amid the economic and social impact of the economic crisis, both business people and scientists have argued the importance of ethical education in business and the need to increase social responsibility (Blasco, 2012; Jagger \& Volkman, 2014). Starting from this necessity, the instrument of data collection (the questionnaire) included questions about discrimination in general, as well as questions concerning discrimination of certain vulnerable groups. 
When asked about the extent to which they themselves discriminate, engineering students responded as follows:

- 35\% considered that they discriminate to a very little extent;

- $62 \%$ felt that they discriminate to a small extent;

- only $3 \%$ considered that they discriminate to a large extent.

Therefore, most respondents $(97 \%)$ believe that they discriminate to a small and very small extent.

On the other hand, however, the students considered in significant percentages that discrimination exists within the Romanian educational system:

- in school - to a very large extent (38\%), to a large extent (42\%), to a small extent (16\%), to a very low extent (4\%);

- in universities - to a very large extent $(9 \%)$, to a large extent (40\%), to a small extent $(43 \%)$, to a very low extent $(8 \%)$.

Thus, a total of 49 percent of the respondents considered that discrimination exists in universities. This result comes to emphasize the imperative need for courses on ethics and nondiscrimination, both for students and teaching staff. The educational establishments (and in particular universities) can and must have a pivotal role in providing ethical and non-discriminatory education and in promoting the importance of moral, ethical and nondiscriminatory behaviors and attitudes, according to their own values, principles, traditions and experiences (Levy \& Rakovski, 2006; Caldwell, 2010; Blasco, 2012; Jagger \& Volkman, 2014). This is the best way to prepare the future professionals for a correct approach at their workplaces.

In fact, $62 \%$ of the students in Engineering believe that, in Romania, there is discrimination at work to a large and very large extent (43\% and 19\% respectively). Thus, a holistic approach in the teaching of ethics is recommended, in which students are encouraged to improve their knowledge and to develop skills in their own personal values framework (Jagger \& Volkman, 2014). Several methods and models of training in this area were proposed and analyzed, in order to increase dialogue, social justice and non-discrimination (Wang, Zhang \& Zhu, 2015). 


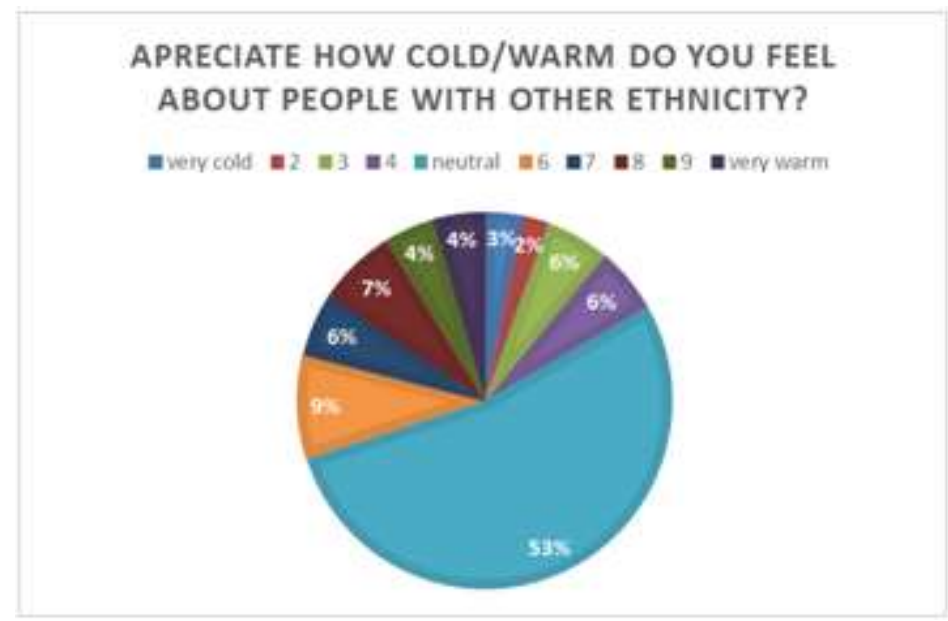

Figure 1: Hot or cold appreciation of students of the Faculty of Engineering in relation to persons of other ethnicity

In relation to persons of other ethnicity, over $15 \%$ of engineering students felt "cold" and $53 \%$ declared themselves neutral in relation to persons of other ethnicity. At the same time, the percentage of those who feel "cold" drops (to $8 \%, 5 \%$ and $7 \%$ respectively) when it comes to disabled people, children, or those terminally ill.

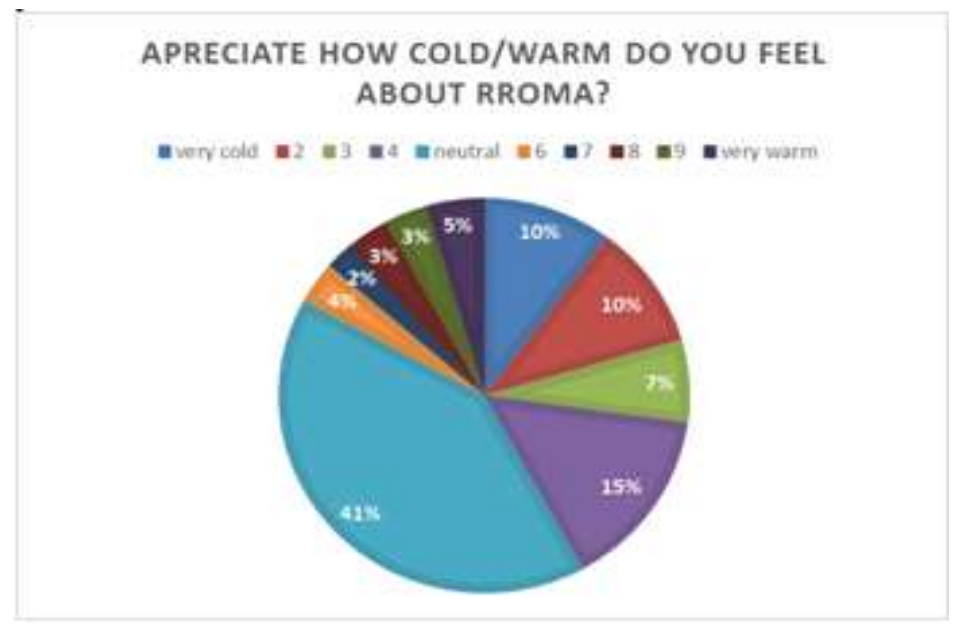

Figure 2: Hot or cold appreciation of students of the Faculty of Engineering in relation to the Roma people

Regarding the attitudes towards Roma population, results show that there is a significant relation between the emotions and cognitions subscales, but none significant relations 
between these components and the behavioral one. Interesting is the fact that there is a relation between what the students think and feel about Roma people, but the emotions and cognitions (thoughts, beliefs) are not reflected in the behavior.

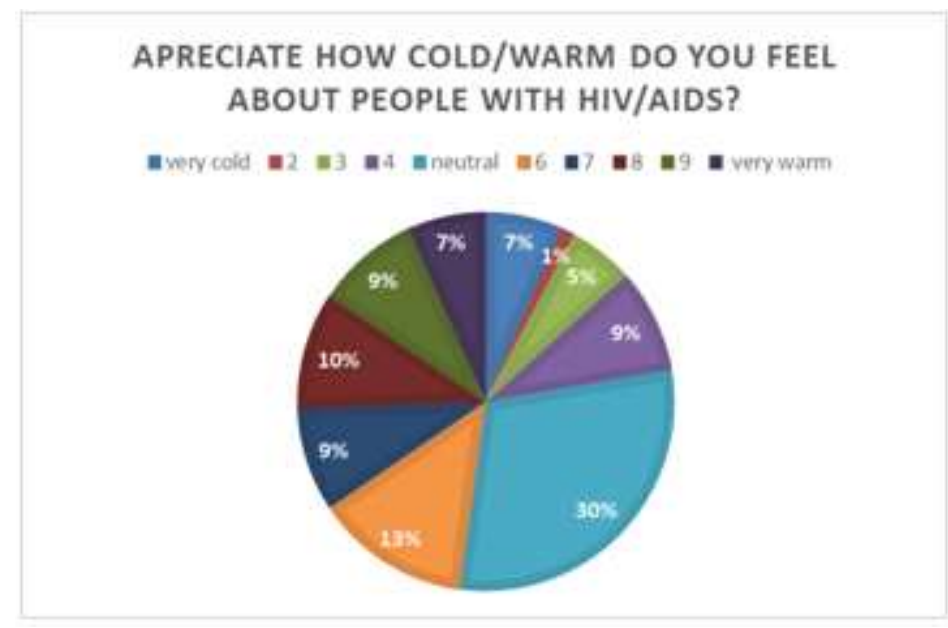

\section{Figure 3: Hot or cold appreciation of students of the Faculty of Engineering in relation to people with HIV/AIDS}

Regarding the attitude towards people infected with HIV/AIDS, the mean of this student group was 55.29, around the middle of the range. The social distance score was 77.38 in the high area, meaning an appropriate distance to the most vulnerable groups. The result about the knowledge regarding the HIV/AIDS disease was 11.37, out of a maximum score of 16 .

\section{CONCLUSION}

The paper outlines the Engineering Faculty students' perception on discrimination in general and on discrimination against certain vulnerable groups in particular, in the context of promoting inclusive societies and of the rebirth of business ethics education at an international level.

The students of the Faculty of Engineering consider that discrimination exists both in school and in universities, even if these institutions must have a primary role in ethics and non-discrimination education. Discrimination is also perceived to be present to a large and very large extent at work, as well as in society as a whole; hence the need for training human resources for the purposes of development of social responsibility of enterprises. Some vulnerable groups (especially the Roma population) are perceived as being more prone to unfair treatment (including in the economic environment), and this justifies furthermore the need to study and prevent discrimination.

As an integral part of social, economic and environmental systems, business organizations 
should assume responsibility for the impact that they have on these systems and on the society that supports their very existence. The necessity for training in ethics and nondiscrimination is also emphasized by the need to balance their goals of obtaining a profit with responsibility for social issues.

\section{ACKNOWLEDGEMENT}

This paper has been supported within the project entitled "Medical higher education oriented towards a non-discriminatory treatment of patients" ID POSDRU/156/1.2/G/142145, co-funded by the European Social Fund, through the Sectorial Operational Program for Human Resources Development 2007-2013, Priority Axis 1 "Education and training in support of economic growth and knowledge-based development of society" Major Field of Intervention 1.2. "Quality in higher education". This project is carried out in the framework of the partnership between "Lucian Blaga" University of Sibiu, as the beneficiary, and the Association for Development and Social Inclusion (ADIS), as a partner, during the period May $14^{\text {th }}, 2014$ - November $13^{\text {th }}, 2015$.

\section{REFERENCES}

Bjerregaard, T., Lauring, J. (2013). Managing contradictions of corporate social responsibility: the sustainability of diversity in a frontrunner firm. Business Ethics: A European Review Volume 22 Number 2

Blasco, M. (2012). Aligning the hidden curriculum of management education with PRME. Journal of Management Education, 36(3), 364-388. http://dx.doi.

org/10.1177/1052562911420213

Bohner, D., Dickel, N. (2011). Attitudes and attitude change. Annual Review of Psychology, 62, 391-417

Caldwell, C. (2010). A ten-step model for academic integrity: a positive approach for business schools. Journal of Business Ethics, 92(1), 1-13. http://dx.doi.org/10.1007/s10551-009-0144-7

Crano, W. D., Prislin, R. (2008). Attitudes and attitude change. New York: Psychology Press

Dipboye, E. L., Colella, A. (2005). Discrimination at work. Mahwah, New Jersey: Lawrence Erlbaum Associates

Dovidio, F. F., Gaertner, S. L. (1998). On the nature of contemporary prejudice: The causes, consequences and challenges of aversive racism. Newbury Park, CA: Sage

Engelen, B. (2011). Beyond markets and states: the importance of communities. UNESCO, Blackwell Publishing Oxford, pp 489-500

Gawronski, B., Bodenhausen, G. V. (2007). Unraveling the processes underlying evaluation: attitudes from the perspective of the APE model. Social Cognition, 25, 687-717

Georgescu, M. A. (2012). Business ethics and organizational values in Romanian enterprises. Procedia Economics and Finance 3 (2012) 734-739

Goela, Mridula and Ramanathan, Preeti E. (2014). Business Ethics and Corporate Social Responsibility - Is there a dividing line? Procedia Economics and Finance 11 (2014) 49-59 
Gülcan, N.Y. (2015). Discussing the importance of teaching ethics in education. Procedia - Social and Behavioral Sciences 174 (2015) 2622-2625

Jagger, S., Volkman, R. (2014). Helping students to see for themselves that ethics matters. The International Journal of Management Education 12 (2014) 177-185

Kacetl, J. (2014). Business Ethics for Students of Management. Procedia - Social and Behavioral Sciences 109 (2014) 875-879

Kurpis, L. V., Beqiri, M. S., \& Helgeson, J. G. (2008). The effects of commitment to moral self-improvement and religiosity on ethics of business students. Journal of Business Ethics, 80, 447-463

Levy, E. S., \& Rakovski, C. C. (2006). A zero tolerance professor and student registration choices. Research in Higher Education, 47(6), 735-754

Olson, J. M., \& Zanna, M. P. (1993). Attitudes and attitude change. Annual Review of Psychology, 44, 117-154

Parmar, B. L., Freeman, R. E., Harrison, J. S., Wicks, A. C., Purnell, L., Colle, S. D. (2010). Stakeholder Theory: The State of the Art. The Academy of Management Annals, 4:1, 403-445, DOI:10.1080/19416520.2010.495581

Perceptii şi atitudini privind discriminarea în România; TNS CSOP Romania; 2012 (http://www.cncd.org.ro/files/file/Raport\%20de\%20cercetare\%20CNCD_Discriminare.pdf , retrieved 23.01.2014)

Percepţii şi atitudini ale populaţiei României faţă de fenomenul de discriminare în 2013; IRES, CNCD; 2013

(http://www.ires.com.ro/articol/247/perceptii-si-atitudini-ale-populatiei-romaniei-fatade-fenomenul-de-discriminare-in-2013, retrieved 23.04.2014)

Rao, S. (2004). Faculty attitudes and students with disabilities in higher education: a literature review. College Student Journal, 28, 191-198

Wang, Q., Zhang W., \& Zhu, Q. (2015). Directing engineering ethics training toward practical effectiveness. Technology in Society, xxx (2015) 1-5

Wankel, C., \& Stachowicz-Stanusch, A. (eds.) (2011). Management education for integrity, Bingley, UK: Emerald Group 